\title{
"Mi Fuma il Cervello" self-portrait series of Alighiero Boetti: evaluation of a conservation and maintenance strategy based on sacrificial coatings
}

\author{
Davide Gulotta ${ }^{*}$, Bruna Mariani ${ }^{2}$, Edoardo Guerrini ${ }^{3}$, Stefano Trasatti ${ }^{3}$, Paola Letardi ${ }^{4}$, Laura Rosetti ${ }^{1}$, \\ Lucia Toniolo ${ }^{1}$ and Sara Goidanich ${ }^{1}$
}

\begin{abstract}
"Mi Fuma il Cervello" ("steaming brain") is the iconic self-portrait of Alighiero Boetti, in which the artist is represented standing up while a copper hose lets water flow on his head. A hidden electric resistance heats the sculpture's head so that the splashing water forms a dense vapour mist as it comes in contact with the hot metal surface. Such system is normally active only during museum exhibitions and determines critical conservation issues due to the inevitable formation of a thick and adherent calcareous deposit. Recently, the Fonderia Artistica Battaglia (Milan, Italy) conducted an extensive conservative intervention aimed at retrieving the original aesthetic features of the bronze surface and its artificial patina finishing. A conservation strategy was proposed based on the use of a superficial coating, to protect the surface and to ease the removal of the calcareous deposits in view of future cleaning operations. Three siliconic commercial paints were selected and preliminarily applied to specimens that simulate the actual alloy. The efficacy, compatibility and durability of the treatments were tested by accelerated ageing test based on combined thermal and wetting cycles, representative of the real working conditions. A multi-analytical diagnostic approach was followed for the evaluation of the coatings characteristics and performances before and after aging: stereomicroscopy, ESEM-EDX, VIS-Light spectrophotometry, micro-FTIR, electrochemical impedance spectroscopy (EIS). The research showed that from the aesthetic point of view all coatings induce only limited and rather comparable initial colour variations. The permanence of the treatments upon ageing, used as durability indicator, was assessed in all cases but the protective layers appeared damaged and no longer continuous over the metal surface. The best performing treatment was identified and further tested with respect to retreatability. The results provide indications for the general conservation and maintenance protocol.
\end{abstract}

Keywords: Bronze, Bronze preservation, Coating, Electrochemical impedance spectroscopy, Monitoring

\section{Background}

"Mi Fuma il Cervello" ("steaming brain") is the iconic bronze self-portrait of Alighiero Boetti, one of the most appreciated Italian conceptual artist mostly known for his series of embroidered pieces of art. The original concept of the self-portrait dates back to the seventies and it was finally realized for the 1993 Sonsbeek exhibition in

\footnotetext{
*Correspondence: davide.gulotta@polimi.it

1 Politecnico di Milano, Dipartimento di Chimica, Materiali e Ingegneria Chimica "Giulio Natta", Piazza Leonardo da Vinci 32, 20133 Milan, Italy

Full list of author information is available at the end of the article
}

Arnhem (The Netherlands). Ugo Vismara made the preliminary gypsum model of the artist himself at the Arnaldo Pomodoro Atelier in Milan. The first bronze statue of a seven-pieces series was then casted from it at Fonderia Artistica Battaglia ${ }^{1}$ [1], with dimensions $205 \times 90 \times 60 \mathrm{~cm} \mathrm{[2].}$

The self-portrait represents the artist standing up and holding a thin copper hose that feeds a stream of water onto his head (Fig. 1). A hidden electric resistance heats the sculpture's head up to $300{ }^{\circ} \mathrm{C}$, so that the splashing

${ }^{1}$ www.fonderiabattaglia.com.
Springer Open

(C) The Author(s) 2017. This article is distributed under the terms of the Creative Commons Attribution 4.0 International License (http://creativecommons.org/licenses/by/4.0/), which permits unrestricted use, distribution, and reproduction in any medium, provided you give appropriate credit to the original author(s) and the source, provide a link to the Creative Commons license, and indicate if changes were made. The Creative Commons Public Domain Dedication waiver (http://creativecommons.org/ publicdomain/zero/1.0/) applies to the data made available in this article, unless otherwise stated. 

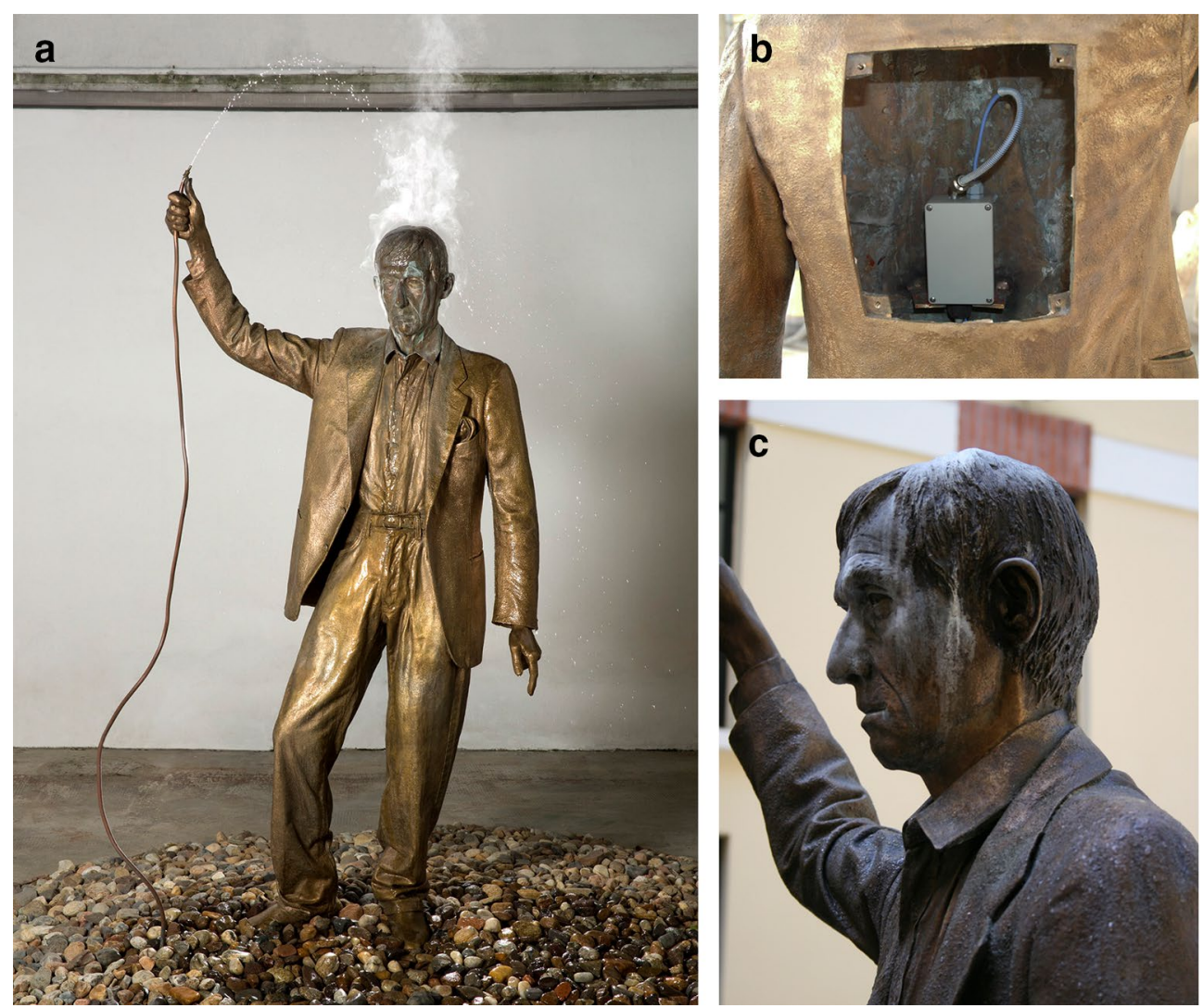

Fig. 1 Photographic documentation of the statue during an exhibition (a); detail of the hidden heating system (b); formation of calcareous deposit as a result of water evaporation (c). All photos courtesy of Alighiero Boetti's Heirs

water, conveyed by a hydraulic system, forms a dense steam as it hits the hot metal surface (Fig. 1a, b). The artistic concept behind this representation refers to the ideation process as a flow of thoughts that literally evaporate from the artist's head. Unfortunately, during the self-portrait exhibition to the public the combined effect of the high temperature and of the fast evaporating water determines critical preservation issues due to the inevitable formation of a thick and adherent calcareous deposit (Fig. 1c) over the head and the shoulders of the statue. Therefore, the maintenance of the statues of the self-portrait series includes a periodic check-up of the heating and hydraulic system, and the cleaning of the bronze surfaces. In particular, frequent cleaning is required because using demineralised water is normally not possible in most exposition conditions so that already after few weeks of display the statues show significant encrustation of calcareous deposits. Given the substantial value of these artefacts, which actually represent an unicum in Alighiero Boetti production, the cleaning operations require a high level of control and selectivity of the removed material. The main challenge is to retrieve the original aesthetic features of the bronze surface while preserving the patina as much as possible. Unfortunately, even the least aggressive cleaning methodology, if frequently repeated, may cause the loss of patina layers and of some sculptural details. The reduction of the impact of such frequent cleaning procedures is therefore one of the main conservative issues to address. A possible strategy would be the use of a sacrificial layer able to delay the formation of the calcareous deposit, to ease its removal and to protect the patina and bronze substrate.

The present investigation was carried out in the framework of an extensive conservative intervention of one of the statues, conducted by Fonderia Artistica Battaglia (Milan, Italy) in view of a major exhibition of Alighiero Boetti's works housed by Galleria Stein in 2014-2015. The aim of the research was the definition of a general conservation protocol for cleaning, protection and for the maintenance of all the statues of the series.

As far as the protection is concerned, it is worth noting that no standards are currently available for the evaluation of transparent coating for metal surfaces of the cultural heritage [3]. The general requirements for coatings applied on such surfaces include: aesthetic compatibility, reversibility, respect of the original material, efficacy 
and maintenance [4]. Coatings are therefore required to induce minimal alteration to the colour and to the overall appearance of the treated substrates, thus preserving the original patina and the presence of corrosion layers. According to reversibility, the protective layer should be removable from the surface even after ageing. The applied product should also be as much effective as possible in reducing the degradation rate over time, thus ensuring an adequate long-term efficacy and maintenance [4]. In the specific case of Boetti's self-portrait, additional requirements arise from the very critical exhibit condition, which can enhance the degradation rate of the protective layers applied onto the surface. A suitable treatment should be able to resist to such conditions, and to be completely removed when it is no longer efficient. The protective materials therefore do not have to undergo chemical alteration because of the high working temperature. Unfortunately, high-temperature corrosion-resistant coatings [5] are mainly developed for industrial applications, e.g. gas turbine engines, and are generally unsuitable for the cultural heritage field, as they do not comply with the specific requirements.

A preliminary survey was therefore conducted among transparent paints available on the market and able to sustain working temperature up to $350{ }^{\circ} \mathrm{C}$, which is higher than that of the statue. Three silicone-based commercial paints were selected and preliminary applied to specimens simulating the actual alloy and finishing of the statue. Such products are not specifically intended for the cultural heritage surfaces and their compatibility for this specific application had to be assessed. The aim of the research was to identify a sacrificial coating to reduce the risk of patina or sculptural detail losses, and to ease the deposits removal. For that it was necessary: (a) to assess the aesthetic compatibility of the coating; (b) to monitor its efficacy over time; and (c) to evaluate the reversibility upon ageing with respect to the ease of removal of the aged coating from the surface. The efficacy, compatibility, durability and reversibility were tested after accelerated ageing test based on combined thermal and wetting cycles, representative of the actual working conditions. A multi-analytical diagnostic approach was applied for the preliminary characterization and the monitoring through stereomicroscopy, SEM and colorimetric measurements. Coatings efficacy and durability were monitored by nondestructive in situ electrochemical impedance spectroscopy (EIS), used to evaluate the initial treatment efficacy and its durability with time. Such technique provides real time information about the degradation rate of the artefact following a non-invasive in situ approach.

Even though the actual exposition conditions of the series can be considered very challenging and rather far from those generally encountered on bronze statues exposed outdoor, the conservation and maintenance strategy here reported, based on the use of sacrificial protective layers, represents a suitable alternative also in more traditional conditions.

\section{Methods}

Bronze specimens were realized with a surface area of about $6 \times 6 \mathrm{~cm}$ and the typical composition of the alloy used by Fonderia Artistica Battaglia (Table 1). The surface finishing of the statue was reproduced on the specimens by creating an artificial patina: specimens were heated up to $120{ }^{\circ} \mathrm{C}$ and brushed with an aqueous solution of $20 \%$ ammonium sulphide.

Three commercial coatings were selected for the testing on the basis of their resistance to high temperature (up to $350{ }^{\circ} \mathrm{C}$ ) and transparency, as reported in technical data sheets. Unfortunately, none of the coatings usually applied to bronze artworks can be used for comparison, as they are unsuitable for high temperature. The commercial products are supplied by Talken (color thermopaint heat resistant), Dupli-color (Supertherm spray) and Saratoga (happy color high temperature).

The coatings were applied by spraying in three layers. Each layer was applied after drying of the previous one. Following application, the silicon paints need proper curing to improve the adhesion with the metal substrate and to provide adequate protection, as stated in the technical datasheets. The recommended curing is $1 \mathrm{~h}$ at $150{ }^{\circ} \mathrm{C}$ for Dupli-color and Saratoga, whereas no indications are provided for Talken. Such a high curing temperature is not suitable in case of cultural heritage objects since it cannot be safely applied in situ or in normal restoration studio. The curing effects on coatings were therefore investigated also at lower temperature to evaluate compositional changes and corrosion protection resulting from the heat treatment. The following conditions were tested: (a) not cured; (b) cured at $50^{\circ} \mathrm{C}$ for $20 \mathrm{~h}$; (c) cured at $150^{\circ} \mathrm{C}$ for $1 \mathrm{~h}$. The compositional changes were studied on the products applied on microscopy glass slides while corrosion resistance was measured on bronze specimens. The 20 -h curing at $50^{\circ} \mathrm{C}$ was selected being more suitable

Table 1 Composition of bronze samples (weight \%)

\begin{tabular}{lllllllllll}
\hline $\mathbf{C u}$ & $\mathbf{P b}$ & $\mathrm{Sn}$ & $\mathrm{Fe}$ & Al & Ni & Mn & Sb & P & Si & Zn \\
\hline 88.22 & 1.81 & 5.57 & 0.10 & 0.00 & 0.21 & 0.00 & 0.04 & 0.03 & 0.00 & 3.91 \\
\hline
\end{tabular}


for in situ treatments, e.g. by using portable IR-lamps. It was decided to use such curing methodology for the tests of coating performances on bronze specimens since it proved to be effective for the specific application (see "Results and discussion" section).

An accelerated ageing procedure was defined to induce a deterioration patterns on the specimens similar to the one occurring to the statue during exhibitions. The accelerated ageing procedure consisted in heating the samples up to $300{ }^{\circ} \mathrm{C}$ while pouring tap water continuously on the surface of the specimens, thus recreating the vapour mist and consequent formation of calcareous deposits. Tap water was used to simulate the most representative and stressing working condition, as it is the one normally available during exhibitions, and to promote the formation of the undesired calcareous deposits. The samples were artificially aged for $100 \mathrm{~h}$, which typically corresponds to a 2-week exhibition period of the statue ( 6 days per week; $8 \mathrm{~h}$ per day).

After aging, the thick calcareous deposits were removed by poultice, using an aqueous solution of $10 \%$ EDTA supported by methylcellulose. The contact time of the poultice was $1 \mathrm{~h}$ and the application was repeated two times. After removal of each poultice, the surface was rinsed with demineralized water. All specimens were characterised before and after the application of the three products, after aging and after deposit removal. In addition, the reversibility of the treatment was evaluated on the best performing product by removing the coating after cleaning of the calcareous deposits with cotton swabs and acetone.

The labelling adopted to identify the surface conditions during the different treatment, aging and cleaning phases is summarised in Table 2.

The photographic documentation of the specimens was made by a Canon Power Shot A2100 IS.

Stereomicroscopic observation was performed with a Leica M250C stereo microscope equipped with a Leica DFC290 digital camera for image acquisition.

Scanning electron microscopy with Energy Dispersive Spectroscopy (SEM-EDS) was performed by using a Zeiss EVO 50 EP instrument equipped with a LaB6 source and $\mathrm{X}$-ray Oxford INCA 200-Pentafet LZ4 spectrometer.

Fourier transformed infrared analyses (FTIR) were performed with a Nicolet 6700 spectrophotometer coupled

\section{Table 2 Labelling of the surface conditions}

\begin{tabular}{ll}
\hline Not treated surface & NT \\
Surface protected with a coating cured at $50{ }^{\circ} \mathrm{C}$ & P \\
Surface protected with a coating and artificially aged & PA \\
$\begin{array}{l}\text { Surface protected with a coating and aged. Calcareous deposit } \\
\text { cleaned with EDTA poultice }\end{array}$ & PAC \\
$\begin{array}{l}\text { Surface protected with a coating and aged. Calcareous deposit } \\
\text { cleaned with EDTA poultice and coating removed with acetone }\end{array}$ & R \\
\hline
\end{tabular}

with a Nicolet Continuum FTIR microscope. Microsamples of the coatings were analysed in diamond compression cells using an MCT detector, with spectral field $4000-600 \mathrm{~cm}^{-1}$.

Colorimetric measurements were performed with a Konica Minolta CM600D VIS light spectrometer to evaluate the aesthetic effect of treatments. The colorimetric coordinates were registered in the CIE L*a*b* colour reference space [6], 10 measurements were performed for each sample evenly distributed on the sample surface. Average values and standard deviations of $\mathrm{L}^{*}, \mathrm{a}^{*}$ and $\mathrm{b}^{*}$ parameters collected in SCI (specular component included) modality were calculated. The global colour variations, $\Delta \mathrm{E}$, were calculated according to the formula reported in the UNI EN-15886 standard [6].

The performances of the protective coatings were assessed by electrochemical techniques. The polarisation resistance $(\mathrm{Rp})$ was derived from linear polarization resistance (LPR) and electrochemical impedance spectroscopy (EIS) measurements. Experiments were performed using a portable potenziostatic device: Ivium Technologies CompactStat equipped with Ivium ${ }^{\circledR}$ software. An electrochemical cell similar to that developed by Letardi and co-authors for in situ measurements [7-9] was used for this work. The cylindrical probe consists of concentric AISI 316 stainless steel counter electrode and reference electrodes embedded in a PTFE holder. The contact between the probe and the working electrode is made through a cloth soaked with commercial soft mineral water as electrolyte (Tables 3, 4).

Table 3 Characteristics of soft mineral water

\begin{tabular}{ll}
\hline Temperature at the water source $\left(^{\circ} \mathrm{C}\right)$ & 15.4 \\
$\mathrm{pH}$ at the temperature of the water source & 7.42 \\
Fixed residual at $180^{\circ} \mathrm{C}\left(\mathrm{mg} \mathrm{I}^{-1}\right)$ & 272 \\
Conductivity at $25^{\circ} \mathrm{C}\left(\mu \mathrm{Cm}^{-1}\right)$ & 415 \\
Free $\mathrm{CO}_{2}\left(\mathrm{mg} \mathrm{I}^{-1}\right)$ & 8 \\
Dissolved $\mathrm{O}_{2}\left(\mathrm{mg} \mathrm{I}^{-1}\right)$ & 6.3 \\
\hline
\end{tabular}

Table 4 Substances dissolved in soft mineral water (mg |-1)

\begin{tabular}{ll}
\hline $\mathrm{Ca}^{2+}$ & 48.6 \\
$\mathrm{Mg}^{2+}$ & 29.4 \\
$\mathrm{Na}^{+}$ & 5.8 \\
$\mathrm{~K}^{+}$ & 1 \\
$\mathrm{HCO}_{3}{ }^{-}$ & 301 \\
$\mathrm{SO}_{4}{ }^{2-}$ & 4.1 \\
$\mathrm{Cl}^{-}$ & 2.4 \\
$\mathrm{NO}_{3}{ }^{-}$ & 8.5 \\
$\mathrm{~F}^{-}$ & 0.15 \\
$\mathrm{SiO}_{2}$ & 15.2 \\
\hline
\end{tabular}


The working electrode was the analyzed sample with an exposed area of $2.27 \mathrm{~cm}^{2}$. LPR measurements were carried out by polarizing the specimen from -10 to $+10 \mathrm{mV}$ with respect to the open circuit potential $\left(\mathrm{E}_{\mathrm{corr}}\right)$ at a scan rate of $0.6 \mathrm{~V} \mathrm{~h}^{-1}$. EIS measurements were carried out in the frequency range $100 \mathrm{kHz}$ to $0.01 \mathrm{~Hz}$ at the open circuit potential by applying an alternating current signal of $0.01 \mathrm{~V}$ peak-to-peak. Rp was calculated from the bode plots [10] and from the slope of the linear polarisation curve. The reported $\mathrm{Rp}$ are the averages of $\mathrm{Rp}$ and LPR measurements with the exception of protected samples for which Rp could not be calculated due to the high insulation provided by the cured coatings.

\section{Results and discussion}

\section{Effect of curing}

The effect of curing was investigated by means of microFTIR (Fig. 2) and electrochemical measurements (Fig. 3). The FTIR analysis of not cured and cured samples of Dupli-color (Fig. 2) exhibited characteristic infrared bands of PDMS (polydimethyl-siloxane). In particular, the peaks in the $2900 \mathrm{~cm}^{-1}$ region and the characteristic peak at $1270 \mathrm{~cm}^{-1}$ are due respectively to the stretching and bending modes of the $\mathrm{C}-\mathrm{H}$ bond; whereas the strong absorption bands located in the $1000-1200 \mathrm{~cm}^{-1}$ region correspond to $\mathrm{Si}-\mathrm{O}-\mathrm{Si}$ stretching mode of the $\mathrm{Si}-\mathrm{O}$ bond. Finally, the $\mathrm{Si}-\mathrm{C}$ absorption peaks of PDMS are located in the $800 \mathrm{~cm}^{-1}$ region [11]. Upon curing, the product progressively loses the ester carbonyl group, centred at $1741 \mathrm{~cm}^{-1}$, most probably due to the presence of a curing agent that favours the cross-linking of the polymeric structure. Actually, all the other absorption peaks remain almost unaltered (as for their positions and relative intensities) as they pertain to the typical chemical structure of the polymer itself.

As far as the coating corrosion protection is concerned, the results of $\mathrm{Rp}$ measurements are reported in Fig. 3. The initial value of $\mathrm{Rp}$ for untreated samples is, as expected, quite low, around $0.6 \pm 0.5 \Omega \mathrm{m}^{2}$. This indicates that the artificial patina does not provide any protection to the bronze substrate. The increase of $\mathrm{Rp}$ for coatings without curing is moderate, between one and two orders of magnitude. The efficacy of the coating with $50{ }^{\circ} \mathrm{C}$ curing is greatly improved, $\mathrm{Rp}$ values being about $10^{5} \Omega \mathrm{m}^{2}$. Since $\mathrm{Rp}$ values are inversely correlated to corrosion rate, the results suggest that the coatings cannot provide an effective protection against corrosion without a proper curing. As it can be observed, a 20-h curing at

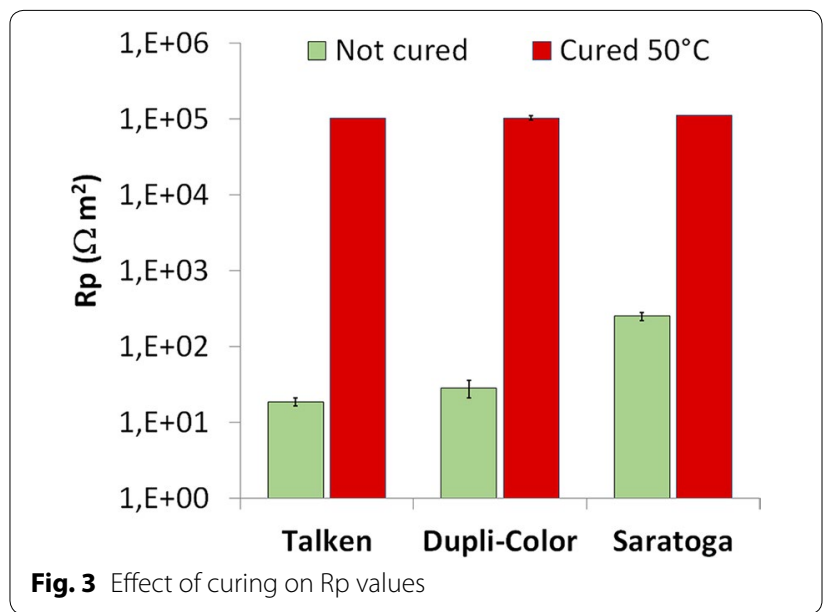

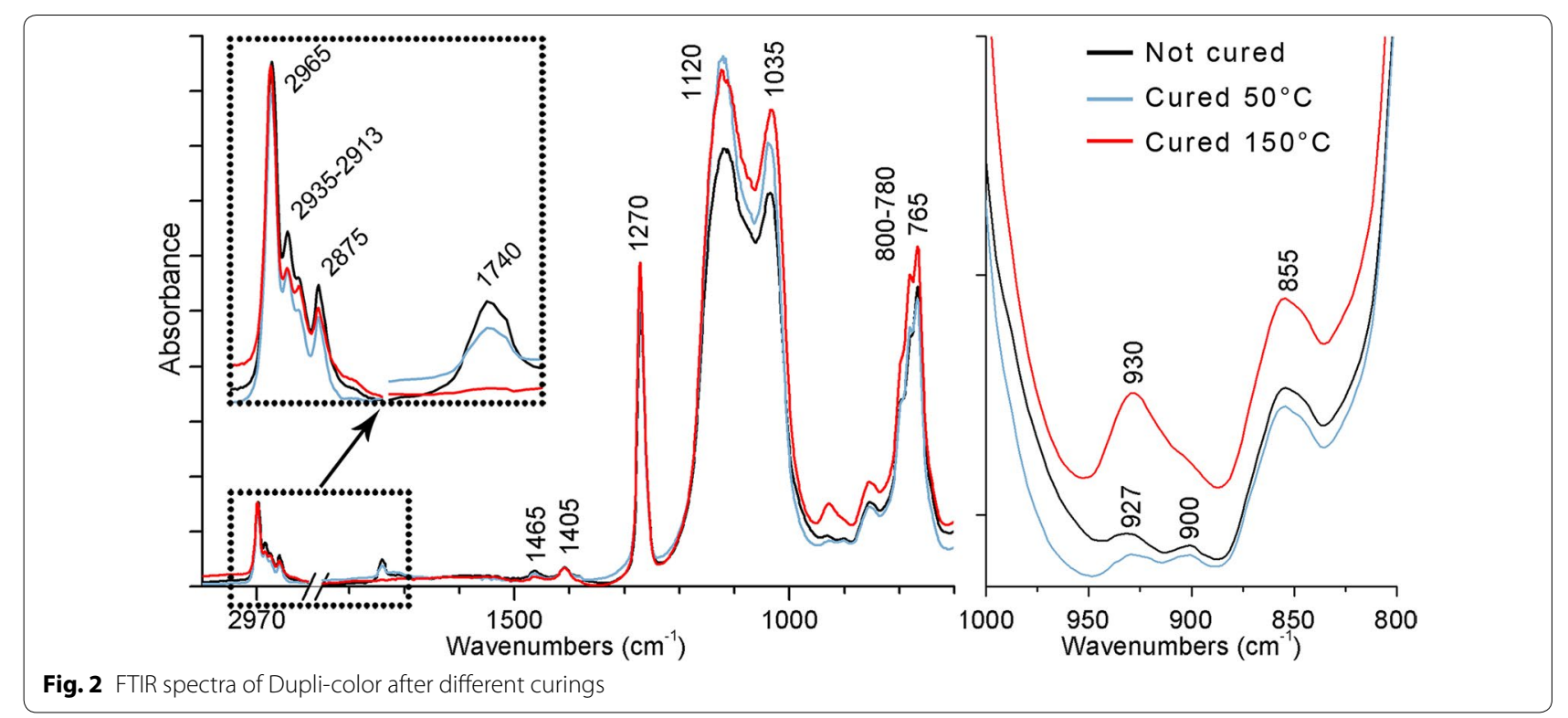


$50{ }^{\circ} \mathrm{C}$ leads to an increase of Rp of three to four orders of magnitude compared to the not cured ones, and therefore to a reduction of the corrosion rate of the same order of magnitude. Consequently, only a $50{ }^{\circ} \mathrm{C}$ curing treatment was considered for the rest of this study. Among the not cured specimens, the best performing product in terms of corrosion protection is Saratoga. Even though the primary purpose of the proposed coatings is not to provide protection against corrosion, to reduce the corrosion rate is always a desirable additional feature of a protective treatment.

\section{Coating compatibility and influence on calcareous deposits}

The artistic casting techniques used for the preparation of the specimens follows the one traditionally employed by the Fonderia Artistica Battaglia artisans and leads to a characteristic superficial appearance of the patinated bronze. Such casting technique is the same used for the portrait series. The resulting surfaces are characterized by high morphological heterogeneity due to the presence of irregular and not perfectly plane areas, small voids, casting residues and web-like discontinuities (Fig. 4, specimens labelled NT). Few scratches and working traces due to the use of mechanical tools can also be observed and are still visible after coating application (Fig. 4, specimens labelled P).

In terms of aesthetic compatibility of the coating, the macroscopic and stereomicroscopic observations of the surfaces do not reveal significant alterations of the surface appearance after application. All the morphological features previously discussed are preserved and only a moderate increase of the superficial gloss and of the colour saturation can be qualitatively assessed (Fig. 4, specimens labelled P). This corresponds to a slightly darker appearance of the treated surface to the naked eye.

The colorimetric measurements confirm the minor decrease of the surface lightness as a result of coating application. Regardless of the applied coating, the $\mathrm{L}^{*}$ values after the treatment are reduced to a negligible extent with respect to standard deviation (Fig. 5), which are

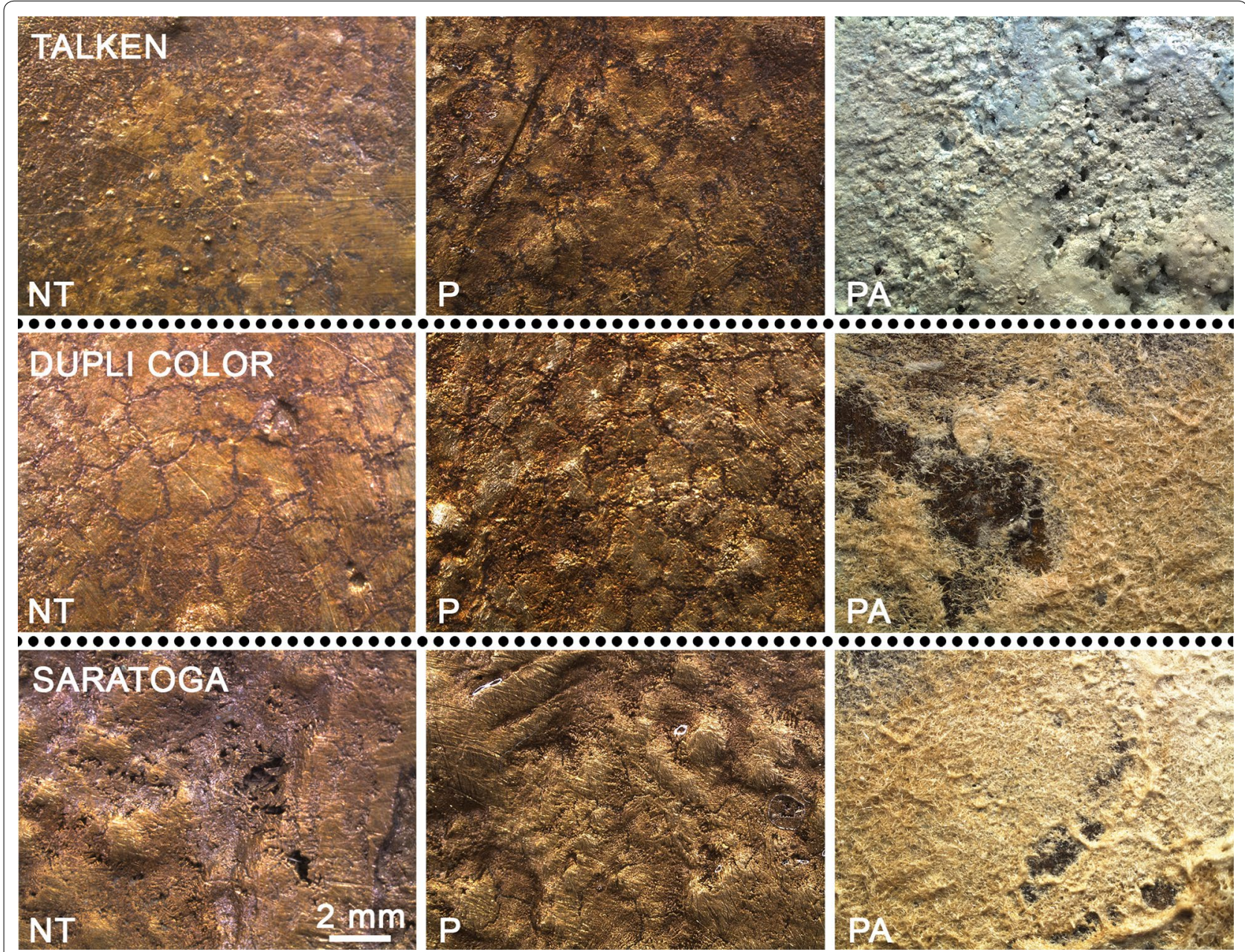

Fig. 4 Stereomicroscopic documentation of the bronze surfaces before (NT) and after the application of the coatings (P), and after ageing (PA) 

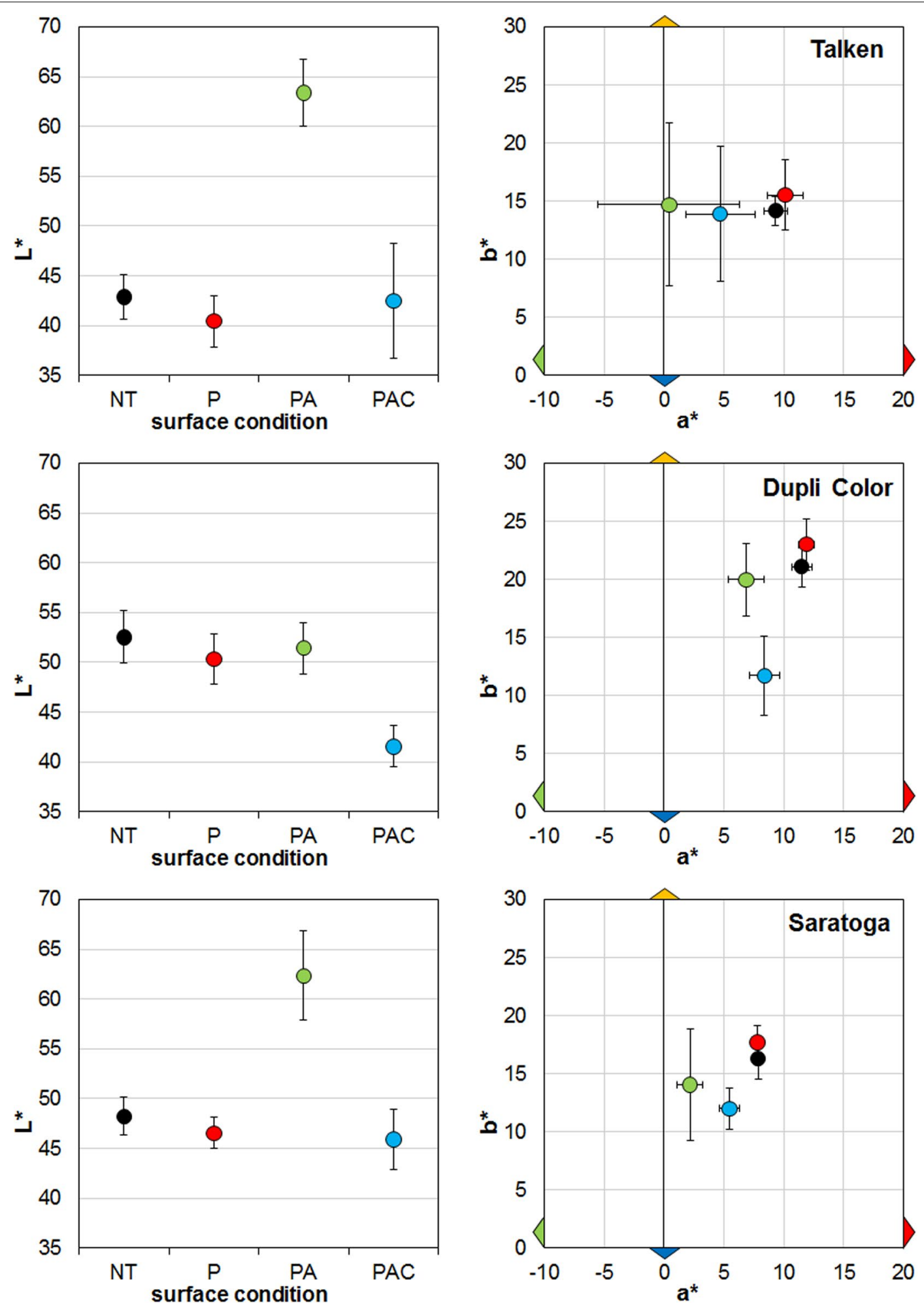

Fig. $5 L^{*}, a^{*}$ and $b^{*}$ values of the surface of the specimen before treatment (NT, black dots) and after: coating application (P, red dots), ageing (PA, green dots) and cleaning (PAC, cyan dots) 
between 2 and 4 units. The chromatic coordinates a* and $b^{*}$ also show changes below the standard deviations (less or equal to 1 for $\mathrm{a}^{*}$, between 1 and 3 for $\mathrm{b}^{*}$ ). For all coatings, the colorimetric coordinate variation is definitely lower than the intrinsic unevenness of untreated bronze specimens. We can thus conclude that all treatments do not alter the colour appearance of the substrates beyond a very slight lightness reduction. Saratoga is the one showing the most limited variation $(\Delta \mathrm{L}=-1.7)$. The global colour variations expressed as $\Delta \mathrm{E}$ are reported in Table 5 and are lower than three in all cases, being almost imperceptible to the naked eye observation [12-14]. All three commercial coatings can therefore be considered compatible for the application in the field of cultural heritage from the aesthetic point of view [12-14].

The combined thermal and wet artificial ageing induced, as expected, the formation of calcareous deposits on the specimens, thus dramatically altering the surface appearance. A thick and rather homogeneous deposit can be observed on the sample treated with Talken (Fig. 4, specimens labelled PA). The deposit has a strong adhesion to the substrate and shows a light blue to green superficial appearance due the thick calcareous formation mixed with corrosion products. This is well described by the colorimetric measurements (Fig. 5, green dots): a sharp rise of the lightness $(\Delta \mathrm{L}=21)$, associated to a significant reduction of the average red component $(\Delta \mathrm{a}=-9)$, which is greater than the pretty large standard deviation both in the red-green $\left(\mathrm{a}^{*}\right)$ and yellowblue (b) direction.

A diffused but not homogenous deposit is formed on Saratoga samples (Fig. 4, specimens labelled PA). In this case the ageing procedure developed an irregularly distributed deposit over the specimen, so that the bronze as well as the overlapped transparent coating can be observed throughout the few discontinuities of the deposit itself. The deposit shows lower adhesion to the substrate with respect to Talken specimen, so that it can be partly removed by mild mechanical actions. The warm

Table 5 Global colour changes calculated between the not treated surface and after coating application (NT-P), and between the not treated surface and after ageing and cleaning of the coating (NT-PAC)

\begin{tabular}{lllr}
\hline & & \multicolumn{1}{c}{$\boldsymbol{\Delta E}$} & \\
\cline { 3 - 4 } & & NT-P & NT-PAC \\
\hline Talken & A & 2.9 & 4.7 \\
Dupli color & B & 2.9 & 14.8 \\
Saratoga & C & 2.2 & 5.5 \\
\hline
\end{tabular}

superficial hue of the aged specimen is characterized also in this case by increased lightness (Fig. 5, green dots) due to the almost white deposit formed $(\Delta \mathrm{L}=14)$, and reduction of the average red component $(\Delta \mathrm{a}=-6)$ less marked than for Talken but with a much lower standard deviation. The standard deviation in the yellow-blue component $\left(b^{*}\right)$ remains, instead, quite high.

The Dupli-color specimen shows the most irregular deposit after ageing. The calcareous encrustation only partially covers the substrate. Due to its limited thickness, the bronze remains still partly visible underneath (Fig. 4, specimens labelled PA). This corresponds to more limited variation of the colorimetric characteristics with respect to the other coatings. The average lightness increase is almost negligible (Fig. 5, green dots), although with much larger standard deviation than the other coatings, due to the discontinuous presence of the deposit. The main effect is the reduction of the average red component $(\Delta \mathrm{a}=-5)$ also in this case. The overall results indicate that the presence of Dupli-color is associated with a reduced formation of the calcareous deposit over the bronze surface, compared to the other treatments.

\section{Removal of calcareous deposits}

Qualitative evaluation of the ease of the cleaning procedure was performed in collaboration with the restorer. The same cleaning methodology was applied to all the aged samples. The addition of the coating facilitates the removal of the calcareous deposits, allowing a less invasive and more cost-effective cleaning operation. As a matter of fact, the adhesion of the deposits, assessed during cleaning, is reduced and the presence of a sacrificial intermediate layer widens the range of suitable cleaning procedures. Therefore, chemical treatments, such as the one previously described with EDTA poultice, can be applied without removing the patina.

It can be observed in Fig. 6 that different cleaning results have been achieved for the three tested coatings. In particular, by macroscopic observation, Talken shows incomplete removal of deposits with non-homogenous distribution of some white residues on the surface, which partially hides the morphological features of the underlying substrate. On the other hand, the cleaning procedure appears significantly more effective and homogeneous on Dupli-color and Saratoga, for which the surface details can be observed through the aged coatings.

Observation of the coatings after cleaning indicates that all of them are still present although differently damaged. The effects of ageing are visible at all scales of observation (Figs. 6, 7). 

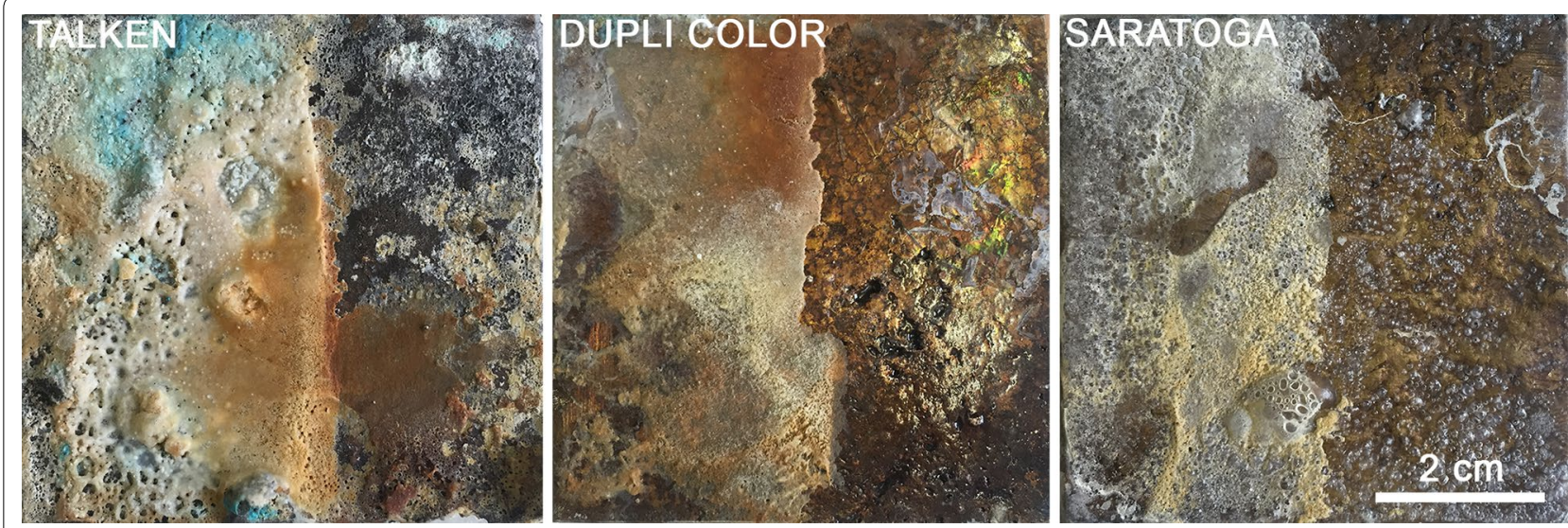

Fig. 6 Macroscopic documentation of the surfaces after $100 \mathrm{~h}$ ageing (left side of the samples) and cleaning (right side of the samples)

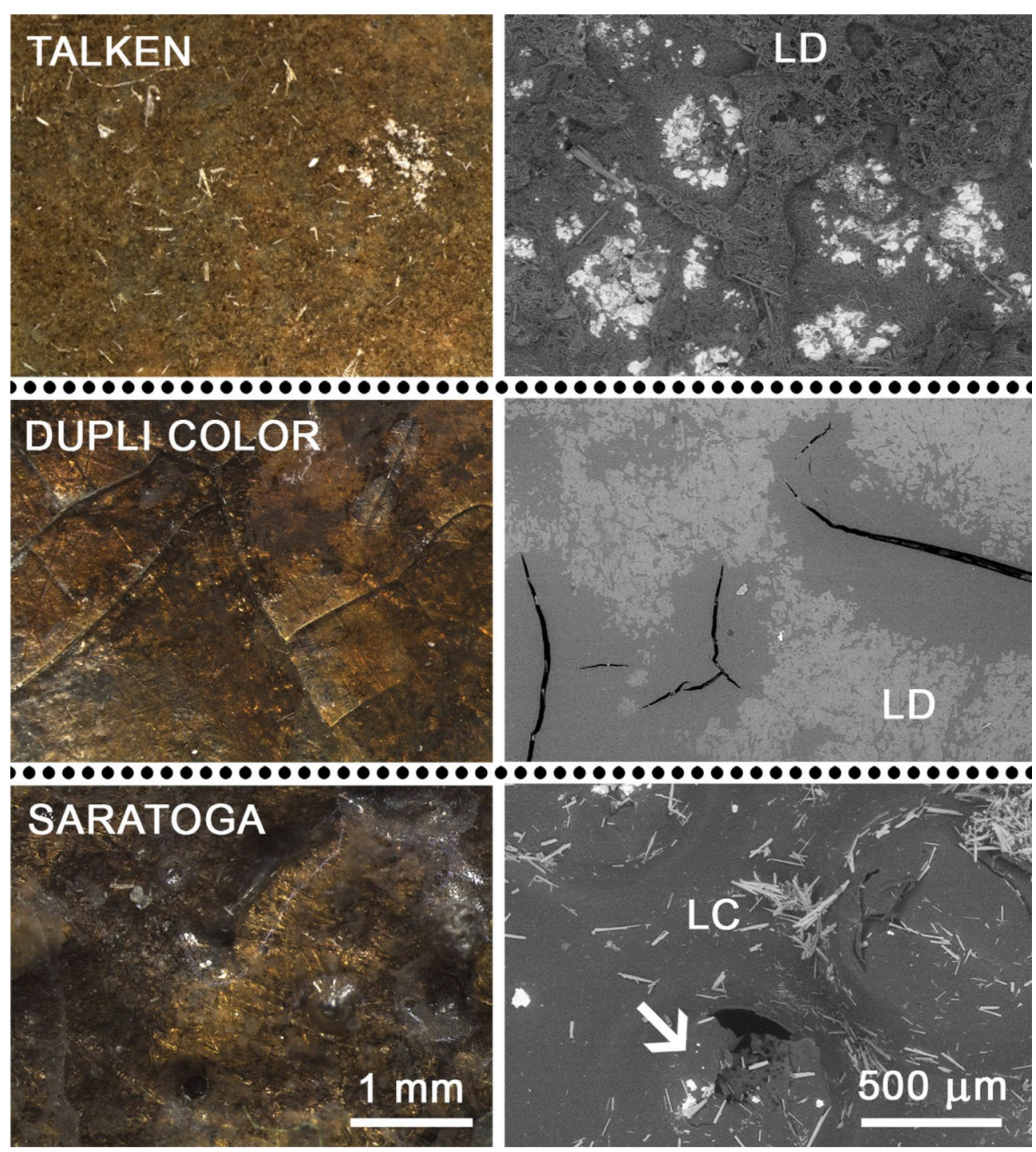

Fig. 7 Stereomicroscopic (left column) and ESEM documentation (right column) of the protected, aged and cleaned specimens. The images shows the presence of residual calcareous deposit (LD) and loose crystals (LC) 
Talken (Fig. 7) shows residual presence of the deposit with needle-like crystals (LD) where the cleaning procedure failed to remove completely the deposit. The ESEM analysis detected also several discontinuities in the coating, which has been partially detached or removed from the substrate. In such areas, the bronze, no longer protected by the coating, is exposed and can be identified by its bright colour in back-scattered analysis mode. The Dupli-color layer after ageing is highly damaged and its surface continuity is therefore compromised (Fig. 7). Diffused fissures and micro-cracks cross the protected surface and fragments of the coatings are detached from the substrate. The ESEM analysis also highlights the presence of thin residues of the deposit (Fig. 7, LD). Some residual crystals from the deposit are still present also on the Saratoga specimen (Fig. 7, LC), which developed a rather different deterioration morphology after ageing. A pattern of bubble-like blistering is formed, leading to localized detachments of the coating. Moreover, where the blisters are partially or completely cracked (Fig. 7, white arrow), the coating no longer forms a continuous layer.

Colorimetric characterization allowed to additionally assess the compatibility of the aged treatments and to evaluate the coating efficacy in increasing the deposit removal, thus acting as an effective protective sacrificial layer. Specimens treated with Talken and Saratoga paints after the deposit cleaning (PAC) get back to $\mathrm{L}^{*}$ values close to those of NT (untreated) and P (protected) surfaces (Fig. 5, cyan dots). The same applies to the $\mathrm{a}^{*}$ coordinate. It has to be noted that in this case the difference with the corresponding NT (untreated) and P (protected) values remains a little bit greater than standard deviations. The dispersion of colour values remains pretty large for Talken, in particular for $L^{*}$ values. On the other hand, the standard deviations of Saratoga are reduced after cleaning to values similar to those of the NT (untreated) and P (protected) surface. This is due to better removal of the deposits on Saratoga treated specimens, whereas some residues are left on Talken.

The specimen treated with Dupli-color paint after deposit cleaning (PAC) underwent the most relevant colour change. This is due to a decrease of lightness associated to a peculiar and intense reduction of $\mathrm{b}^{*}$. In addition, a moderate reduction of the $\mathrm{a}^{*}$ coordinate is observed as for the other coatings.

The overall colour results after ageing and cleaning allow to state that the Saratoga specimen shows the last relevant colour alteration, which consists mainly in reduced saturation of the hue with respect to the not treated one. The global colour changes after cleaning (PAC) with respect to the initial not treated bronze surfaces (NT) are reported in Table 5. Talken and Saratoga show similar results, whereas the variation induced by Dupli-color is considerably higher.

Corrosion protection, stability and durability of treatments Even though corrosion protection is not the main goal of the proposed "sacrificial" coatings, the reduction of the corrosion rate would be a highly desirable additional feature of the treatment. As previously commented, all proposed coatings provide good initial protection of the specimens against atmospheric corrosion (Fig. 3). However, it is worth reminding that the real statues are subjected to very critical conditions during exhibitions that may result in rapid deterioration of the coatings. Differences in terms of corrosion protection after aging are therefore crucial for the selection of the best performing coating: a high final protection outcome is not only desirable, but is also correlated to stability and durability of the applied product.

In Fig. 8, Rp values of samples without protectives (NT) are compared with Rp values of protected samples before (P) and after (PAC) aging and cleaning. The reported Rp values for NT and PAC surfaces are the average of all EIS and LPR results. In the case of P surfaces, Rp values derives only from EIS measurements, since on coated surfaces LPR often does not provide reliable results due to the high electrical insulation resulting from the treatment.

After accelerated aging, the three proposed treatments show quite a different performance despite the very similar initial behaviour. They all present marked reduction of $\mathrm{Rp}$ values, that indicates reduction of the protection provided by the coating. Among all, Saratoga shows the lowest loss of protection, notwithstanding the surface pattern of cracked bubbles observed by SEM. As a matter of fact, although its surface continuity appears compromised, $\mathrm{Rp}$ values of aged Saratoga paint is still about

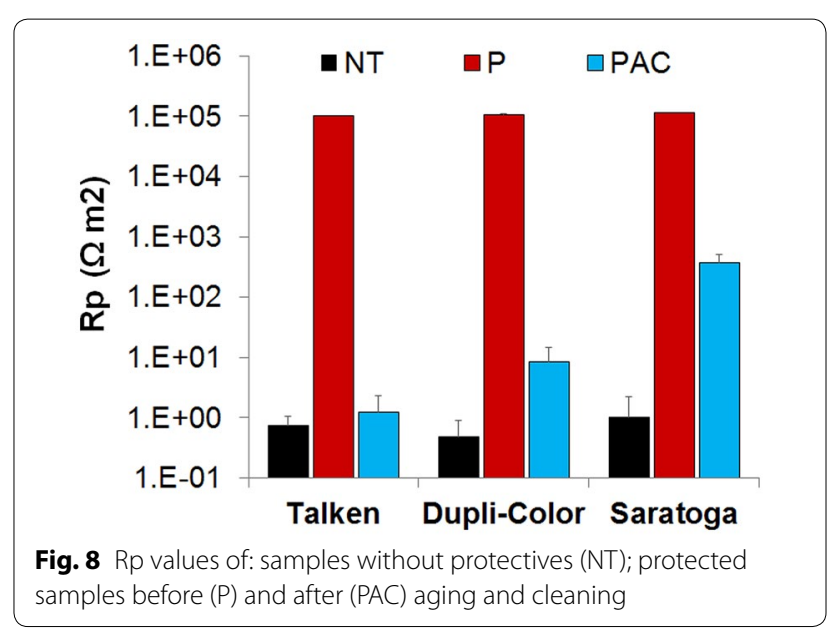


two orders of magnitude higher than the untreated samples. Dupli-color paint provides lower protection against corrosion after aging compared to Saratoga, showing Rp values that are only one order of magnitude higher than the untreated surface. The worst performance is given by Talken, which presents $R p$ values after aging very close to the untreated samples, indicating that this type of coating does not provide a durable protection against corrosion after aging.

The overall results show that the morphological deterioration of the protective layers resulting from ageing is always associated to a drop of the performance in terms of corrosion protection. The FTIR characterization, on the other hand, indicates that only Dupli-color presents significant alteration also from the chemical point of view (Fig. 9). In particular, after ageing the Dupli-color product loses the characteristic $\mathrm{Si}-\mathrm{CH}_{3}$ groups, as indicated by the drastic decrease of the intensity of the $\mathrm{Si}-$ $\mathrm{CH}_{3}$ stretching peak located at $2965 \mathrm{~cm}^{-1}$ and of the bending one at $1270 \mathrm{~cm}^{-1}$; as a result, the efficacy of the polymeric coating as water repellent is progressively lost. Moreover, the backbone of the polymeric structure is dramatically altered, as it can be argued from the variations in both position and relative intensities of the $\mathrm{Si}-\mathrm{O}$ stretching peaks at 1120 and $1035 \mathrm{~cm}^{-1}$.

\section{Selection of the most suitable coating}

Considering the overall results, Saratoga was identified as the most suitable sacrificial treatment. It showed the best performances in term of corrosion protection and durability, as well as an overall good aesthetic compatibility in terms of global colour variation. Also Talken can be considered a suitable choice, however it was not selected considering its reduced corrosion protection properties after aging compared with Saratoga. On the other hand, Dupli-color has to be discarded because of its low durability with respect to corrosion protection and to low chemical stability under severe aging condition. Furthermore, despite the apparent reduction of the deposit formation, that was very efficiently removed from the surface, it displayed low aesthetic compatibility as it underwent the most significant colour changes after aging and deposit removal.

\section{Check of the reversibility of the best performing coating}

As previously discussed, reversibility in terms of possibility to completely remove a coating without damaging the substrate is a highly desirable requirement, although not always achievable, for any surface protection treatment of the cultural heritage. This is even more important in the case of a sacrificial layer, like the one proposed in this work, which is meant to be reapplied several times during the life of the artwork. Colorimetric and ESEM analyses have been performed in order to evaluate the removal efficacy of the aged coating.

The colorimetric characterisation of the surface after the removal of the aged and cleaned Saratoga paint (R) shows that the global colour change with respect to the untreated surface is very low $(\Delta \mathrm{E}=2.0)$. This value is significantly lower than the one calculated between the untreated (NT) and the aged and cleaned coating (PAC), as previously discussed (Table 5). This last is therefore mainly due to the alteration of the coating itself and to the minor contribution of the residual deposit.

The reversibility of the treatment with respect to the extent of its removal from the surface has also been

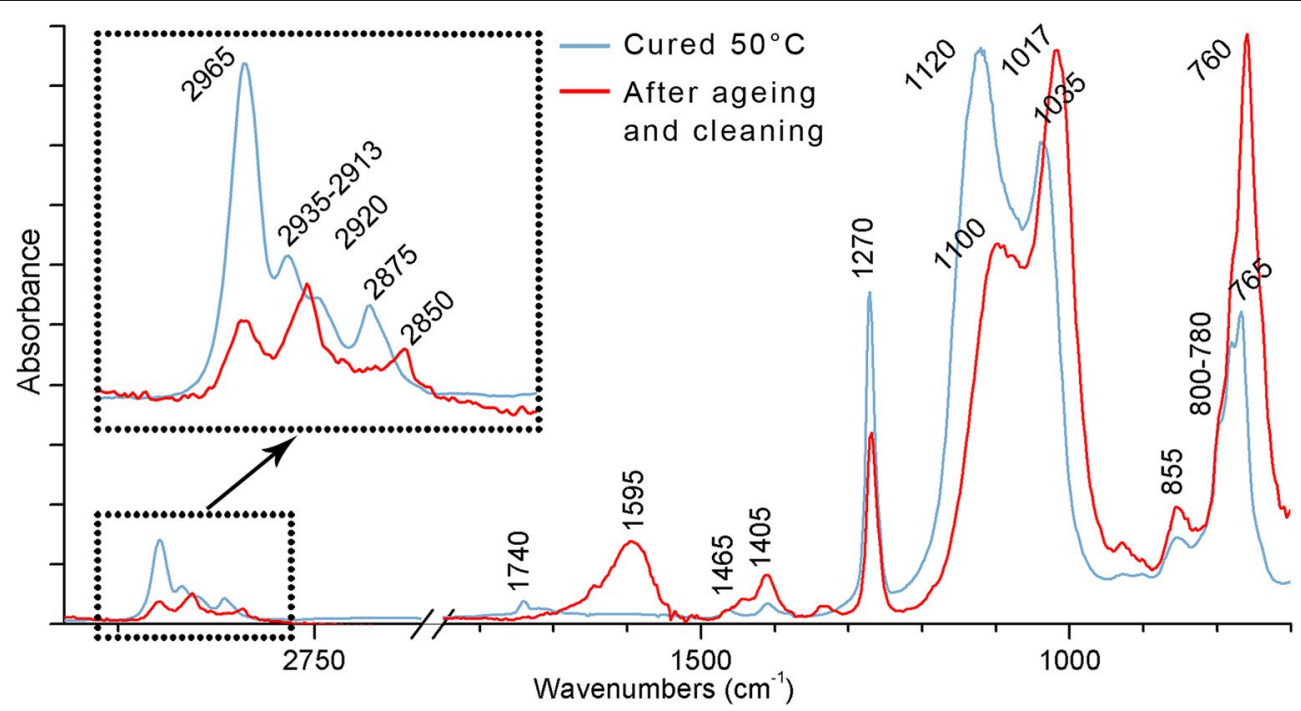

Fig. 9 FTIR spectra of Dupli-color after curing (red line) and after ageing and cleaning (blue line) 
assessed by stereomicroscopy (Fig. 10a), which shows good removal with no visible sign of residual coating. After removal, surface details and working signs initially observed are preserved. The ESEM analysis confirmed the removal efficacy (Fig. 10b). From the morphological point of view, a clear difference can be observed between the protected and cleaned area (Fig. 10c) and the one where the aged coating has been removed (Fig. 10e). The former is still covered by a continuous layer of coating showing the presence of residual calcium-based crystals, whereas, upon removal, the characteristic microstructure of the bronze substrate is exposed. From the compositional point of view, carbon and silicon belonging to the coating are the main elements present on the cleaned surface, together with minor calcium due to the residual presence of the calcareous deposit (Fig. 10d). On the other hand, the area of coating removal shows prevalence of copper and zinc which can be attributed to the bronze alloy, while sulphur belongs to the patina (Fig. 10f). Carbon is strongly reduced and silicon is no longer detectable. The overall data therefore confirm the reversibility of Saratoga as indicated by the removal results.
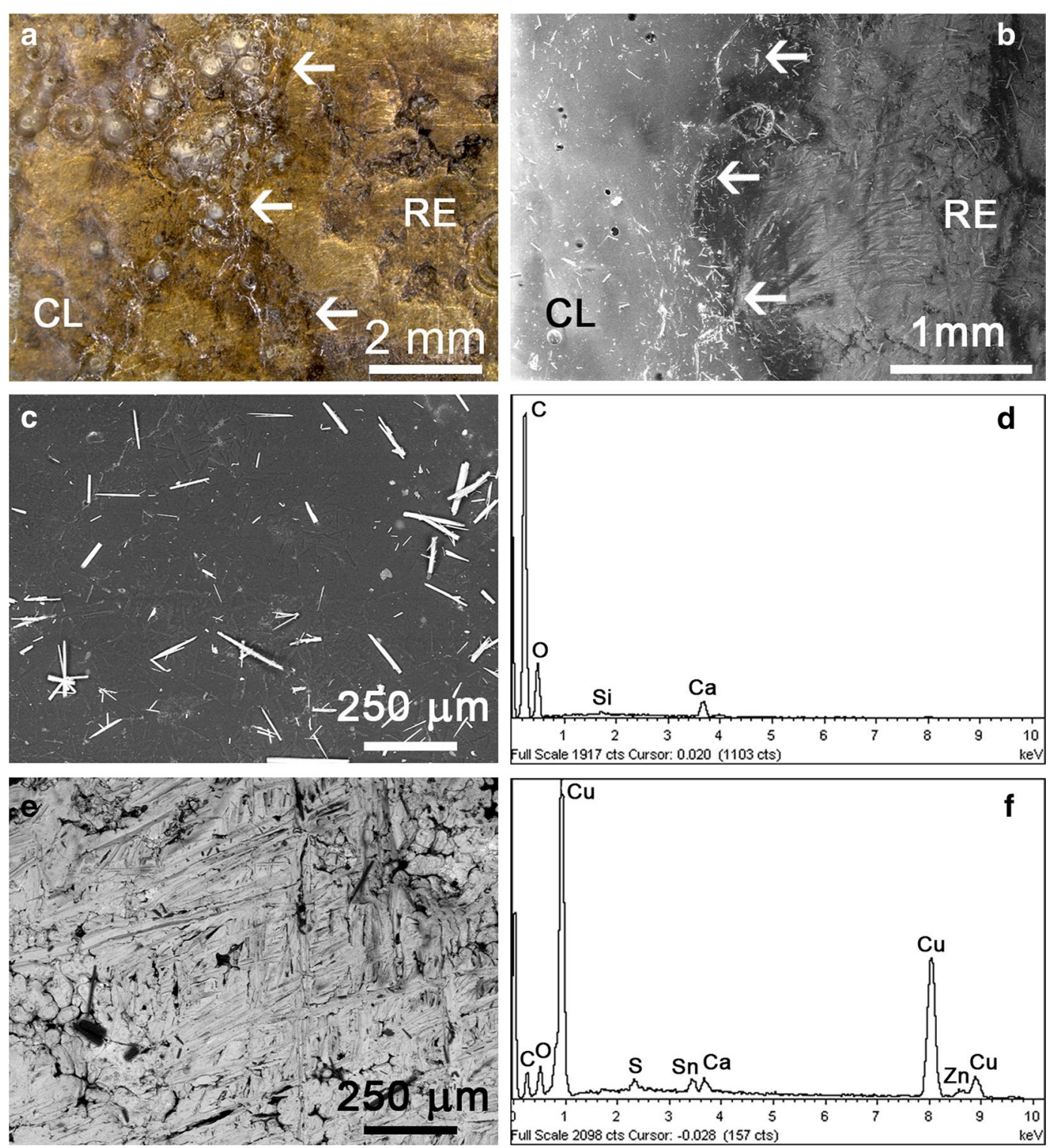

Fig. 10 Stereomicroscopic (a) and ESEM (b) observation of the border (indicated by the white arrows) separating the surface still protected with Saratoga after cleaning $(\mathrm{CL})$ and the one after the removal of the coating (RE). Details of the surface morphology and EDX analyses of the treated area $(\mathbf{c}-\mathbf{d})$ and of the removed one $(\mathbf{e}-\mathbf{f})$ 


\section{Conclusions}

The conservation of Alighiero Boetti's self-portrait series presents very severe problems. In order to reduce the possible damage related to the periodic cleaning operations, the use of a sacrificial layer as part of the maintenance strategy has been proposed. Three transparent commercial paints for high temperature applications, but not specifically intended for cultural heritage surfaces, have been evaluated with respect to their overall compatibility, durability, efficacy after ageing and re-treatability. The selected coatings require a high temperature curing (around $150{ }^{\circ} \mathrm{C}$ ) to ensure the best performances in working conditions. Preliminary tests were performed on not cured and on low temperature cured $\left(50{ }^{\circ} \mathrm{C}\right)$ specimens in order to define a sustainable methodology that could be applied also in actual museum conditions. Results confirmed that curing is necessary, but it can be conducted even at low temperatures without hindering the paint performances.

According to the conservation requirements, the overall results indicate that Saratoga and Talken paints are suitable for the specific application. On the other hand, Dupli-color was discarded because of its chemical alteration, reduced compatibility and extremely low corrosion protection after aging.

Saratoga was identified as the best performing material due to its higher durability and better performance in terms of corrosion protection after aging compared with the other products. The selected paint also fulfilled the re-treatability requirement as it proved to be completely removable from the substrate without damaging the surface. Moreover, the removal operation can be easily carried out by means of an organic solvent following a cost-effective and low time-consuming methodology. In addition, the use of a sacrificial coating resulted convenient from the operative point of view since it facilitates the cleaning of the calcareous deposits. The proposed approach can therefore be implemented within the general maintenance protocol for the preservation of the complete series of portraits. In addition, a similar approach based on the use of sacrificial protective layers can also be considered as valid conservation strategy in case of more traditional works of art and in presence of less aggressive exposure conditions.

\section{Authors' contributions}

DG and SG conceived the study, performed part of the analyses, carried out the interpretation of the results and drafted the manuscript. BM prepared the specimens, carried out the treatments, cleaning and removal operations. EG and ST contributed to the electrochemical analysis, the interpretation of the data and critically reviewed the manuscript. LR performed part of the analyses and participated in the interpretation of the results. PL and LT participated in the data interpretation and critically reviewed the manuscript. All authors read and approved the final manuscript.

\section{Author details}

${ }^{1}$ Politecnico di Milano, Dipartimento di Chimica, Materiali e Ingegneria Chimica "Giulio Natta", Piazza Leonardo da Vinci 32, 20133 Milan, Italy. ${ }^{2}$ Dipartimento di Restauro, Fonderia Artistica Battaglia, Milan, Italy. ${ }^{3}$ Dipartimento di Chimica, Università degli Studi di Milano, Milan, Italy. ${ }^{4}$ Institute of Marine Science, National Research Council, Genoa, Italy.

\section{Acknowledgements}

Not applicable.

Competing interests

The authors declare that they have no competing interests.

\section{Publisher's Note}

Springer Nature remains neutral with regard to jurisdictional claims in published maps and institutional affiliations.

Received: 6 February 2017 Accepted: 3 April 2017

Published online: 17 May 2017

\section{References}

1. Bosio D, Crespi S, Loverini Botta C. Fonderia Artistica Battaglia. In: Visconti di Modrone B, editor. Industria Grafica Signum s.r.l.; 2008.

2. In: Amman JC, editor. Alighiero Boetti: catalogo generale. Milano: Electa Mondadori; 2009

3. Argyropolous V, Boyatzis S, Giannoulaki M. The role of standards in conservation methods for metals in cultural heritage. In: Dillmann P, Watkinson D, Angelini E, Adriaens A, editors. Corrosion and conservation of cultural heritage metallic artefacts, European Federation of Corrosion. Cambridge: Woodhead Publishing Ltd; 2013. p. 478-517.

4. Cano E, Lafuente D, Bastidas DM. Use of EIS for the evaluation of the protective properties of coatings for metallic cultural heritage: a review. J Solid State Electrochem. 2010;14:381-91.

5. Mévrel R. State of the art on high-temperature corrosion-resistant coatings. Mater Sci Eng A. 2016;120:13-24.

6. UNI EN-15886. Conservation of cultural property. Test methods. Colour measurements of surfaces; 2010.

7. Letardi P. Outdoor bronze protective coatings: characterisation by a new contact-probe electrochemical impedance measurements technique. In: The science of art. Padova: Edizioni Libreria Progetto di Padova; 2002. p. 173-8.

8. Letardi P. Laboratory and field tests on patinas and protective coating systems for outdoor bronze monuments. In: Ashton EJ, Hallam D, editors. Metal 04, Proceedings of the international conference metals conservation. Canberra: National Museum of Australia; 2004. p. 379-87.

9. Letardi P, Spiniello R. Characterisation of bronze corrosion and protection by contact-probe electrochemical impedance measurements. In: Metal 2001: Proceedings of the international conference metals conservation. Santiago: Western Australian Museum; 2001

10. Zhang XY, He WL, Wallinder IO, Pan J, Leygraf C. Determination of instantaneous corrosion rates and runoff rates of copper from naturally patinated copper during continuous rain events. Corros Sci. 2002;44:2131-51.

11. Tellez L, Rubio J, Rubio F, Morales E, Oteo JL. FT-IR study of hydrolysis and polymerization of tetraethyl orthosilicate and polydimethyl siloxane in the presence of tetrabutyl orthotitanate. Spectrosc Lett. 2004;37:11-31.

12. García O, Malaga K. Definition of the procedure to determine the suitability and durability of an anti-graffiti product for application on cultural heritage porous materials. J Cult Herit. 2012;13:77-82.

13. Meng B, Mueller U, Garcia O, Malaga K. Performance of a new anti-graffiti agent used for immovable cultural heritage objects. Int J Archit Herit. 2014;8:820-34.

14. Mokrzycki W, Tatol M. Color difference delta E-A survey. Mach Graph Vis. 2011;20:383-411. 